\title{
Experimental Study of 2-Methoxyethanol Steam Reforming in a Membrane Reactor for Pure Hydrogen Production
}

\author{
Ali Hedayati ${ }^{*}$, Jordi Llorca ${ }^{a}$ \\ ${ }^{a}$ Institute of Energy Technologies, Universitat Politècnica de Catalunya, EEBE, Barcelona, \\ Spain
}

ali.hedayati@upc.edu , jordi.llorca@upc.edu

"Corresponding author: Ali Hedayati

Institute of Energy Technologies, Universitat Politècnica de Catalunya, EEBE, Barcelona, Spain, ali.hedayati@upc.edu

\section{Abstract}

For the first time, 2-methoxyethanol $\left(\mathrm{C}_{3} \mathrm{H}_{8} \mathrm{O}_{2}\right)$ was used for producing pure hydrogen in a catalytic membrane reactor (CMR) via steam reforming (SR). The SR experiments were performed at $923 \mathrm{~K}$ and 1-10 bar using a mixture of 2-methoxyethanol (MEX) and water at $\mathrm{S} / \mathrm{C}$ ratio of 3 . Moreover, SR experiments were performed under the same operating conditions using ethylene glycol (EG), methanol (MET), and a mixture of EG+MET, keeping a constant carbon molar flow rate into the CMR to study the reaction pathway through which 2-methoxyethanol is converted to $\mathrm{SR}$ products $\left(\mathrm{CH}_{4}, \mathrm{CO}, \mathrm{CO}_{2}\right.$, and $\left.\mathrm{H}_{2}\right)$. Hydrogen recovery values of up to $90 \%$ and pure hydrogen yields of 0.5 and 0.63 at 10 bar were reached in the case of the steam reforming of MEX and EG+MET, respectively. An outstanding value of $4 \mathrm{~mol}$ of pure hydrogen per mol of MEX was obtained at $10 \mathrm{bar}$. The presence of methanol promoted the SR of EG. The experimental results showed that 
2-methoxyethanol is a promising source for producing hydrogen, especially in a CMR where a better efficiency (complete fuel conversion and high hydrogen yield) is reached.

\section{Keywords:}

2-methoxyethanol, ethylene glycol, steam reforming, membrane reactor, pure hydrogen

\section{Introduction}

As an alternative to fossil fuels, hydrogen is considered as a clean energy carrier that can be combusted similar to the conventional carbonaceous fuels or be converted efficiently to electricity by fuel cells [1]. In this regard, production of a hydrogen rich stream by steam reforming (SR) of hydrocarbons or oxygen containing organic compounds has been investigated vastly $[2,3]$. Methane, methanol (MET), ethanol, acetic acid, and ethylene glycol (EG) are among the fuels most used as the source of hydrogen in steam reforming processes [2-10]. Apart from the prevalent fuels, the use of larger molecules such as dimethoxymethane (DMM) and trimethoxymethane (TMM) have attracted attention recently for production of hydrogen-rich gas via SR [11-13] or direct oxidation in low temperature fuel cells [13-15]. High hydrogen yield (steam-reformed easily), high H/C ratio, and absence of $\mathrm{C}-\mathrm{C}$ bond are mentioned as the advantages of such molecules regarding the SR process $[11,12]$.

Similarly, the experimental results for hydrogen production via SR of 2-methoxyethanol (methyl cellosolve, $\mathrm{C}_{3} \mathrm{H}_{8} \mathrm{O}_{2}$ ) have been reported in a few works [13,16]. 2-methoxyethanol (MEX) has a lower $\mathrm{H} / \mathrm{C}$ ratio compared to ethanol $(\mathrm{H} / \mathrm{C}=3)$ but equal to $\mathrm{EG}$ or $\mathrm{DMM}$ $(H / C=2.6)$. The preliminary results of methoxyethanol steam reforming (MEX SR) 
experiments show high hydrogen yield (higher than methanol and ethanol steam reforming) and low carbon deposition at high temperature and high steam to carbon $(\mathrm{S} / \mathrm{C})$ ratio, i.e. in presence of excess water $[13,16]$. MEX does not occur as a natural product, but it can be manufactured easily from methanol and ethylene oxide [17]. Methanol can be obtained by fermentation of biomass (bio-methanol) and ethylene oxide is synthesized via direct oxidation of ethylene. Renewable pathways for producing ethylene via conversion of biomass [18], bio-ethanol [19], and biological methods [20,21] have been studied recently. Therefore, there is a promising perspective of renewable production of MEX via conversion of biomass and natural resources.

Regarding pure hydrogen production, catalytic membrane reactors (CMRs), where the generation and separation of hydrogen take place simultaneously, are beneficial in terms of producing pure hydrogen (in the case of dense metallic membranes) and higher process efficiency [22,23]. The shift effect that occurs in CMRs results in even higher hydrogen yields because the presence of a membrane selective to the hydrogen permits attaining very high conversion values in comparison with the traditional reactors operating under the same conditions [24]. In fact, CMRs represent a modern configuration in which an integrated reaction/separation unit has many potential advantages: reduced capital costs, improved yields and selectivity towards hydrogen and drastically reduced downstream separation costs $[25,26]$. Among CMRs, palladium-based membrane reactors fulfill the requirements to obtain an ultra-pure hydrogen stream (full hydrogen perm-selectivity) suitable for low-temperature fuel cell feeding $[9,10,27]$. Palladium membranes are among the oldest membranes studied for gas permeation and separation applications and are still the membranes with the highest hydrogen permeability and selectivity [28].

In this work, MEX was used for hydrogen production via catalytic steam reforming over $\mathrm{RhPd} / \mathrm{CeO}_{2}$ catalyst in a membrane reactor equipped with $\mathrm{Pd}-\mathrm{Ag}$ dense metallic 
membranes, aiming to produce fuel cell-grade hydrogen. We investigated the catalytic reactivity and the performance of the CMR in terms of selectivity towards hydrogen and the production rate of pure hydrogen. Further, the reaction mechanism was studied and a reaction pathway for MEX SR was suggested. $\mathrm{RhPd} / \mathrm{CeO}_{2}$ was the catalyst selected due to its activity toward breakage of $\mathrm{C}-\mathrm{C}$ bond, robustness, low coke formation, and high selectivity towards hydrogen [29]. To the best of our knowledge, this is the first time that MEX SR, EG SR, and the related reaction mechanisms are studied for pure hydrogen production in a membrane reactor.

\section{Material and methods}

\subsection{Experimental setup}

The $\mathrm{RhPd} / \mathrm{CeO}_{2}$ catalyst $(0.5 \% \mathrm{Rh}-0.5 \% \mathrm{Pd})$ was deposited over cordierite pellets of about 1-3 mm following the procedure described by López et al. [30]. The laboratory setup used for the SR experiments (fuel reformer) consisted essentially of a fuel tank, a liquid pump, a catalytic membrane reactor (CMR), a pressure transducer and a condenser. The scheme of the experimental setup and the CMR is presented in Fig. 1.

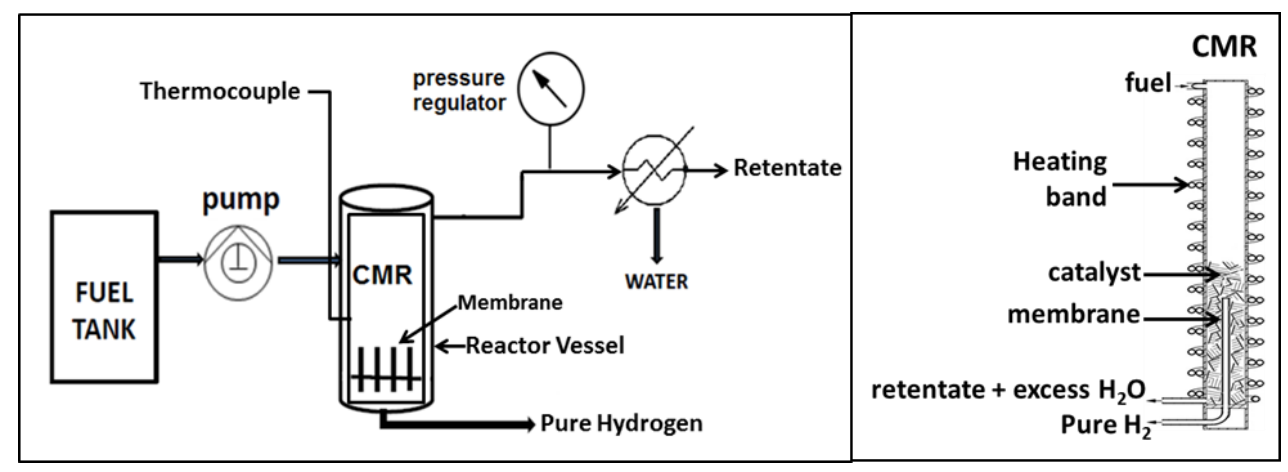

Fig. 1: Scheme of the catalytic membrane reactor (CMR) 
A heating tape was wrapped around the reactor wall and was controlled by a PID electronic controller (Fuji PXR4) connected to K-type thermocouples. A HPLC pump (Knauer) was used to pump the mixture of distilled water and MEX/MET/EG and to keep the pressure. A backpressure regulator (Swagelok) adjusted the retentate pressure. No pressure regulation was implemented on the permeate side, so the permeate side pressure was kept at ambient pressure. No sweep gas was used so pure hydrogen was obtained at atmospheric pressure.

The reactor was $10 \mathrm{in.} \mathrm{tall} \mathrm{and} 1 \mathrm{in}$. in diameter. There were four Pd-Ag membrane tubes highly selective to hydrogen inside the reactor; each one $3 \mathrm{in.}$ tall and 1/8 in. diameter in order to separate hydrogen. The membrane tubes consisted of Pd-Ag (30 $\mu$ m layer) supported on porous stainless steel (PSS) provided by REB Research \& Consulting, MI, USA, accounting for $30.4 \mathrm{~cm}^{2}$ total active membrane area. The reactor was filled with 26 grams of the $\mathrm{RhPd} / \mathrm{CeO}_{2}$ catalyst so that the metallic membranes were fully covered. The composition of the non-condensable portion of the outlet gas (retentate) was analyzed using an online Gas Chromatograph (Agilent 3000A MicroGC equipped with MS 5 Å, PlotU and Stabilwax columns). The condensable portion of the outlet gas was collected from the condenser and analyzed by gas chromatography (Shimadzu GC-2100 Plus) for the presence of any unconverted carbon-containing species. The flowrate of pure hydrogen (permeate side) was measured with a dedicated mass flow meter (Bronkhorst F-111B) and the flow rate of the retentate gas was measured with a conventional bubble meter.

MEX SR experiments were performed using a mixture of 2-methoxyethanol (Acros Organics, $99+\%)$ and water at S/C (steam to carbon) ratio of 3. The experimental conditions are given in table 1 . The SR experiments were performed firstly without membrane (outlet valve of the permeate side of the CMR closed, no hydrogen permeation) and then with hydrogen permeation through the membrane (outlet valve of the permeate 
side of the CMR open). The experiments with the open valve (hydrogen permeation) were run at 6,8 , and 10 bar because of very low hydrogen permeation rate at lower pressures. The gas hourly space velocity (GHSV) was calculated as the ratio between the volumetric gas flowrate of the reactants $\left(M E X / E G / M E T+\mathrm{H}_{2} \mathrm{O}\right)$ with respect to the reactor volume.

Table 1: Experimental conditions

\begin{tabular}{lc}
\hline Temperature $(\mathrm{K})$ & 923 \\
Pressure (bar) & $1-10$ \\
Fuel flow rate $\left(\mathrm{ml}_{\mathrm{liq}} / \mathrm{min}\right)$ & 0.1 \\
S/C & 3 \\
GHSV $\left(\mathrm{h}^{-1}\right)$ & $130-150$ \\
\hline
\end{tabular}

\subsection{Data analysis}

Apart from the pure hydrogen production rate, hydrogen yield $\left(\mathrm{Y}_{\mathrm{H}_{2}}\right)$ and hydrogen recovery $\left(\mathrm{R}_{\mathrm{H}_{2}}\right)$ were calculated based on the experimental results to evaluate the performance of the CMR.

$Y_{H_{2}}=\frac{F_{H 2 . p e r m}}{8 \times F_{M E X}}$

$R_{H_{2}}=\frac{F_{H 2 . p e r m}}{F_{H 2 . t o t a l}}$ 
Where $F_{H 2 \text {. perm, }} F_{M E X}$, and $F_{H 2 \text {. total }}$ are pure hydrogen permeation rate, MEX inlet flow rate, and total hydrogen production rate, respectively, in mol/s. Total hydrogen production included the permeated hydrogen and the hydrogen content of the retentate gas.

The SR of MEX is assumed to start with the hydrolysis of the molecule, which results in the production of MET and EG:

$\mathrm{C}_{3} \mathrm{H}_{8} \mathrm{O}_{2}+\mathrm{H}_{2} \mathrm{O} \rightarrow \mathrm{CH}_{3} \mathrm{OH}+\mathrm{C}_{2} \mathrm{H}_{6} \mathrm{O}_{2}$

Followed by the steam reforming of MET and EG presented in reactions 4 and 5 , respectively:

$\mathrm{CH}_{3} \mathrm{OH}+\mathrm{H}_{2} \mathrm{O} \rightarrow 3 \mathrm{H}_{2}+\mathrm{CO}_{2}$

$\mathrm{C}_{2} \mathrm{H}_{6} \mathrm{O}_{2}+2 \mathrm{H}_{2} \mathrm{O} \rightarrow 5 \mathrm{H}_{2}+2 \mathrm{CO}_{2}$

Therefore, eight moles of hydrogen are produced theoretically per converted mole of MEX at complete conversion of MEX:

$\mathrm{C}_{3} \mathrm{H}_{8} \mathrm{O}_{2}+4 \mathrm{H}_{2} \mathrm{O} \rightarrow 8 \mathrm{H}_{2}+3 \mathrm{CO}_{2}$

The suggested mechanism was studied in the CMR by performing SR experiments using EG (Scharlau, 99.5\%) and MET (Labkem, 99.8\%) separately and a mixture of MET and EG under the same experimental conditions as those presented in Table 1, keeping the molar flow rate of inlet carbon (MEX, EG+MET, EG, or MET) around $1.2 \times 10^{-3} \mathrm{~mol} / \mathrm{min}$.

\section{Results and discussion}

\subsection{Methoxyethanol steam reforming}

No carbon-containing compounds including unconverted MEX, EG, and MET were detected in the retentate. The analysis of the condensate showed less than $0.5 \%$ of carbon-containing compounds. Therefore, it is assumed that all the intermediates are 
converted to $\mathrm{CO}, \mathrm{CH}_{4}, \mathrm{CO}_{2}$, and $\mathrm{H}_{2}$ followed by methane steam reforming (MSR) and water gas shift (WGS) reactions (eq. 7 and 8 , respectively).

$\mathrm{CH}_{4}+\mathrm{H}_{2} \mathrm{O} \leftrightarrows 3 \mathrm{H}_{2}+\mathrm{CO}$

$\mathrm{CO}+\mathrm{H}_{2} \mathrm{O} \leftrightarrows \mathrm{H}_{2}+\mathrm{CO}_{2}$

\subsection{2-methoxyethanol SR experiments without $\mathrm{H}_{2}$ permeation}

Prior to the permeation tests, the performance of the CMR was studied at 1-10 bar maintaining the outlet valve of the permeate side of the CMR closed (no hydrogen permeation). As shown in Fig.2, the production rates of $\mathrm{H}_{2}$ and $\mathrm{CO}_{2}$ decline with pressure in accordance to the Le Chatelier's Principle. In the case of methane, the production rate increase until $P=6$ bar, which is ascribed to the reverse MSR (methanation, eq. 7 ).

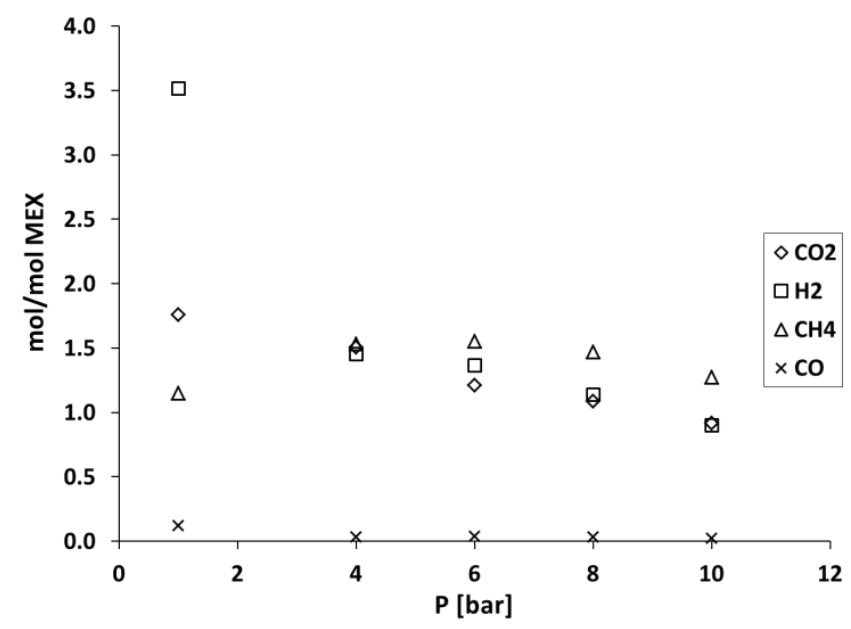

Fig. 2: Production rates of MEX SR gases without membrane

At $P>6$ bar the production rate of methane decreases, which is due to carbon deposition as expected at high pressures. According to the mechanisms suggested by Wang et al. [8], carbon can be formed at the expense of methane at high pressure: 
$\mathrm{CH}_{4} \leftrightarrow 2 \mathrm{H}_{2}+\mathrm{C}$

Carbon balance over the inlet and outlet of the reactor, as presented in Table 2, proves the deposition of carbon in the CMR as carbon recovery (ratio between molar flow rate of outlet to inlet carbon) declines with pressure in the gas phase (no carbon-containing compounds in the condensate phase).

Table 2: Carbon recovery for MEX SR with closed membrane (no $\mathrm{H}_{2}$ permeation)

\begin{tabular}{cc}
\hline P [bar] & $\begin{array}{c}\text { carbon recovery in gaseous } \\
\text { products (out/in) [\%] }\end{array}$ \\
\hline 1 & 100 \\
4 & 100 \\
8 & 94 \\
10 & 87 \\
\hline
\end{tabular}

The production rate of $\mathrm{CO}$ is remarkably lower than the other gaseous products, which proves the reactivity of the catalyst for the WGS reaction.

\subsection{MEX SR experiments with open membrane $\left(\mathrm{H}_{2}\right.$ permeation)}

As stated by the Sieverts' law, the hydrogen permeation rate through dense metallic membranes is a temperature activated phenomena driven by the difference between the 
partial pressure of hydrogen at the two sides of the membrane, that is, the retentate side (inside the reactor, around the membrane) and the permeate side (right after the membrane) $[30,31]$. In the MEX SR experiments carried out in the CMR with the operative membrane, complete MEX conversion is maintained and up to four moles of pure hydrogen are produced per mole of MEX. This is remarkable enhancement of hydrogen production with respect to the experiments performed without membrane. As shown in Fig.3, less methane appears in the retentate stream in the CMR operated with the membrane, which is attributed to the promoted MSR reaction as an evident result of the shift effect introduced by the membrane. The reactions are pushed towards the product side (higher conversion to hydrogen and carbon dioxide) as a result of hydrogen permeation through the Pd-Ag membrane [32].

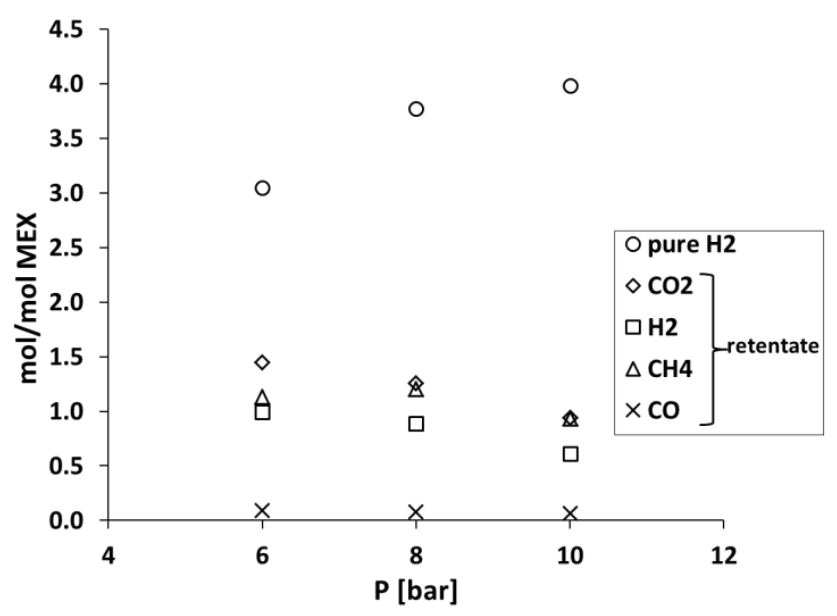

Fig. 3: Production rates of MEX SR gases in the CMR with open membrane

The carbon recovery at 6, 8, and 10 bar are 89 and 84, and 64\%, respectively. Compared to Table 2 (membrane closed), clearly more carbon is formed when the membrane is open. This can be attributed to eq. 9 considering the effect of the membrane to remove hydrogen in the reactor. Thus, the decreasing trend of methane in the retentate with pressure can be due to two phenomena, i.e. MSR reaction towards more hydrogen 
production, and decomposition of methane to form carbon. Pressure has a negative effect also on the $\mathrm{CO}_{2}$ production rate, which may be equally due to carbon deposition.

Hydrogen yield is a well-known indicator of the performance of fuel reformers. According to eq. 1, hydrogen yield can ideally reach up to one if 8 moles of pure hydrogen are obtained and permeated through the membrane per 1 mole of inlet MEX. On the other hand, hydrogen recovery is a measure of the ability of the CMR to produce pure hydrogen. This refers essentially to the membrane performance and obviously high values are required due to the high cost of the Pd-Ag membranes. The hydrogen yield and recovery as a function of pressure are presented in Table 3.

Table 3: Hydrogen yield and recovery for MEX SR

\begin{tabular}{ccc}
\hline$P$ [bar] & Hydrogen yield $\left(\mathrm{Y}_{\mathrm{H}_{2}}\right)$ & Hydrogen recovery $\left(\mathrm{R}_{\mathrm{H}_{2}}\right)$ \\
6 & 0.38 & 0.75 \\
8 & 0.47 & 0.81 \\
10 & 0.50 & 0.87 \\
\hline
\end{tabular}

Following the trend of the pure hydrogen production rate (Fig.3), hydrogen yield and recovery increase with pressure. In the case of hydrogen recovery, the increase of the values with pressure show the ability of the CMR to recover more hydrogen at higher pressures as the hydrogen permeates through the membrane according to the Sieverts' law. Thanks to the brilliant catalytic reactivity and membrane performance, as more hydrogen is permeated, more $\mathrm{CH}_{4}$ and $\mathrm{CO}$ are converted. Consequently, a hydrogenproducing loop is formed where the equilibrium limitations of MSR and WGS reactions are conquered due to the shift effect introduced by the membrane and higher efficiency of the CMR is reached. 


\subsection{Ethylene glycol and methanol steam reforming}

SR experiments of ethylene glycol (EG), methanol (MET), and their mixture (EG+MET) were performed at the same S/C ratio as MEX SR reaction tests. The production rate of hydrogen per mole of carbon in the inlet for the different fuels obtained in the CMR without membrane is given in Fig. 4.

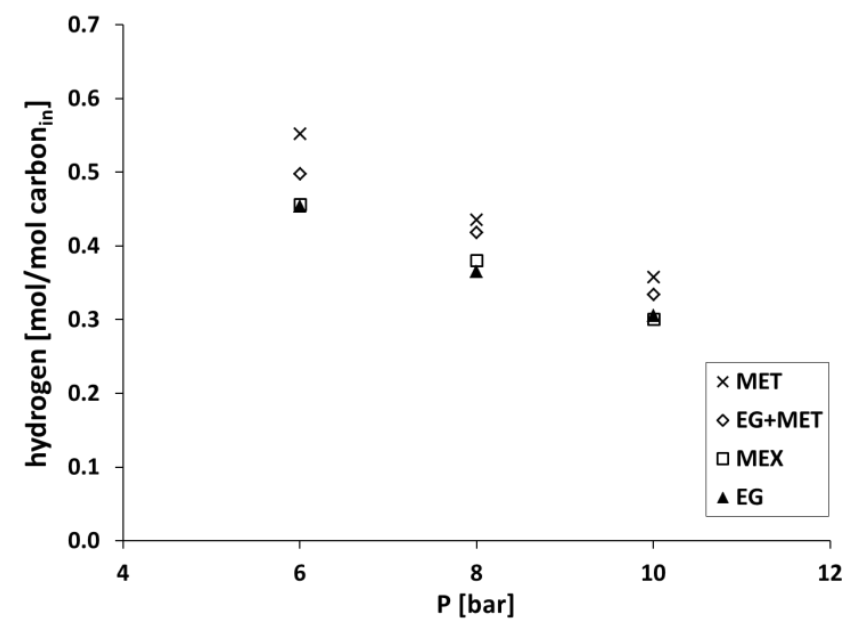

Fig. 4: Hydrogen production rates per mol of carbon in the inlet $\left(\right.$ carbon $\left._{\text {in }}\right)$ obtained without membrane

As discussed before for the MEX SR experiments, the decreasing hydrogen production rates at increasing pressure in the four different cases is due to equilibrium limitations. The higher production rates of hydrogen in the case of MET SR are attributed to the absence of C-C bonds.

As presented in Table 4, when the SR reactions are carried out in the CMR with the membrane open, there is a positive effect of pressure on both hydrogen permeation and SR promotion as expected. The best results in terms of pure hydrogen production are obtained in the case of EG+MET. Based on equations 4 and 5, the hydrogen yield in the 
case of SR of the mixture of ethylene glycol and methanol (EG+MET) is defined as (eq. 10):

$Y_{H_{2}}=\frac{F_{H 2 . p e r m}}{5 \times F_{E G}+3 \times F_{M E T}}$

Where $F_{E G}$ and $F_{M E T}$ are the inlet flow rates of ethylene glycol and methanol, respectively.

Table 4: Hydrogen yield and recovery obtained in the SR experiments in the CMR with open membrane

\begin{tabular}{|c|c|c|c|c|c|c|}
\cline { 2 - 7 } \multicolumn{1}{c|}{} & \multicolumn{3}{c|}{$\mathrm{Y}_{\mathrm{H}_{2}}$} & \multicolumn{3}{c|}{$\mathrm{R}_{\mathrm{H}_{2}}$} \\
\hline $\mathrm{P}$ [bar] & EG+MET & EG & MET & EG+MET & EG & MET \\
\hline 6 & 0.31 & 0.16 & 0.24 & 0.70 & 0.54 & 0.62 \\
\hline 8 & 0.53 & 0.28 & 0.46 & 0.84 & 0.75 & 0.82 \\
\hline 10 & 0.63 & 0.38 & 0.49 & 0.90 & 0.87 & 0.86 \\
\hline
\end{tabular}

Interestingly, the hydrogen yield is significantly higher in the EG+MET SR experiments with respect to those carried out separately with EG and MET under the same operating conditions, which indicates that there is a cooperative effect between these two molecules during the SR process over the $\mathrm{RhPd} / \mathrm{CeO}_{2}$ catalyst. The study of the reason of this cooperative effect and the exact reaction steps of the mechanism of the SR process is beyond the scope of this work.

The mixture of $E G+M E T$ yields more hydrogen at high pressure $(P>6$ bar) compared to MEX (Tables 3 and 4). This is in accordance to the fact that, prior to SR, MEX needs to be 
hydrolyzed to a mixture of EG and MET, which subsequently reform into the gaseous products (eq. 3-5). In other words, in the experiments carried out with EG+MET the SR is direct, whereas in the experiments performed with MEX it is necessary a previous step to hydrolyze MEX. The production rates of the EG+MET SR gases are presented in Fig. 5.

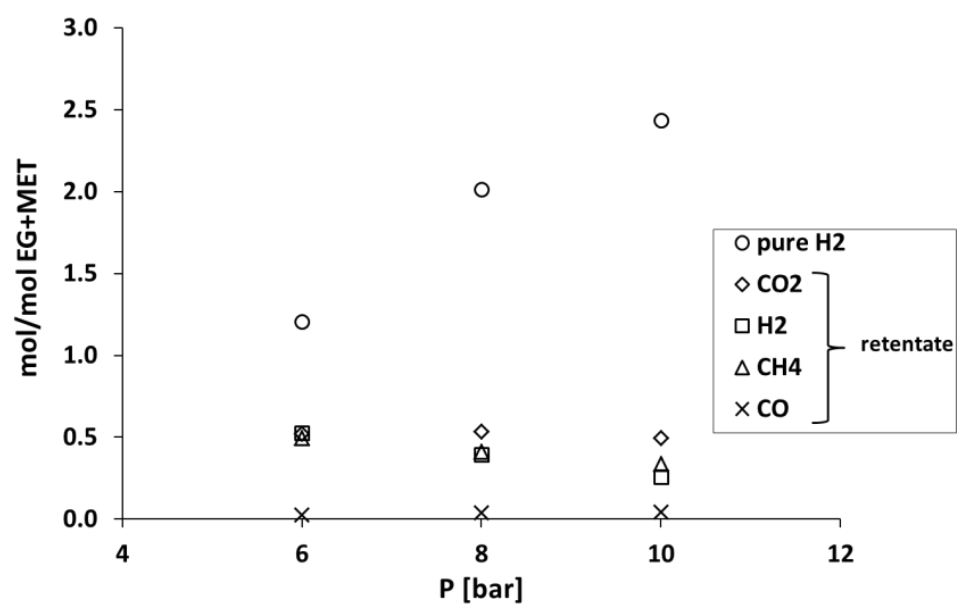

Fig. 5: Production rates of EG+MET SR gases in the CMR with open membrane

Compared to Fig.3, less molar production rates are obtained for all the species. This comparison highlights two important features. Firstly, better performance is clearly seen in the case of MEX SR (Fig.3) in terms of the production rate of pure hydrogen. Secondly, although less methane is generated in the case of steam reforming of EG+MET, low molar rate of carbon dioxide compared to Fig.3 denotes a hidden reaction pathway probably leading to coke formation (see also Fig.6). As presented by eq.9, Wang et al. [8] suggested that methane decomposition or Boudouard reaction may result in coke formation in the EG steam reforming environment. Moreover, short residence times and low S/C ratio may promote coke formation [33,34]. 


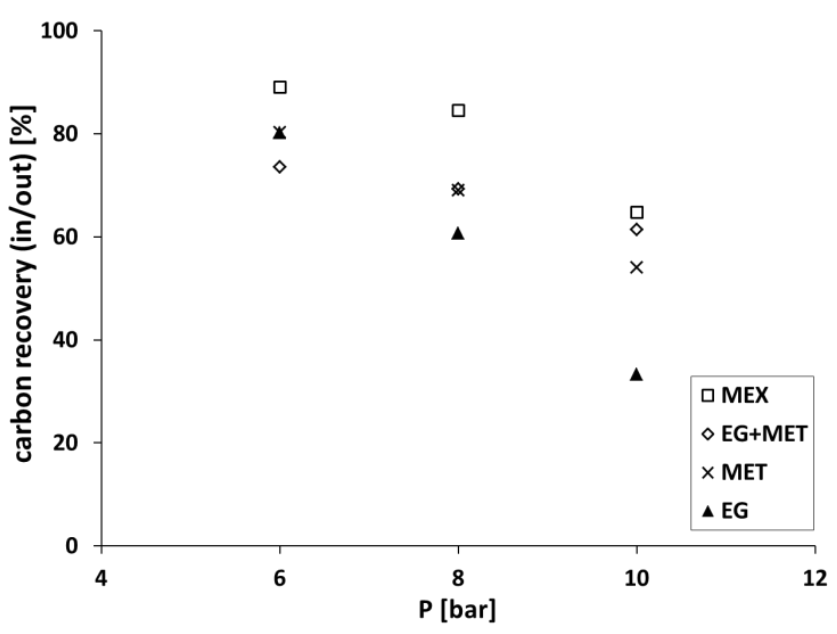

Fig.6: Carbon recovery with pressure in the case of open membrane

Concerning carbon deposition (Fig. 6), the carbon balance is clearly worse in the case of the EG SR experiments, particularly at higher pressure values, which are preferred for hydrogen recovery as discussed previously. The carbon recovery at higher pressure follows the trend MEX>EG+MET>MET>>EG. The cooperative effect between EG and MET in the SR process is also evidenced in terms of carbon deposition.

It is interesting to note that the ratio between the molar flow rate of inlet hydrogen (by fuel and water, denoted as $\mathrm{H}_{2}^{\text {in }}$ ) and inlet carbon (by fuel, denoted as $\mathrm{C}^{\mathrm{in}}$ ) is higher in the case of EG SR compared to MEX SR experiments (Table 5), so the higher availability of hydrogen atoms at the surface of the catalyst during EG SR does not result in lower coke formation. One may speculate that the facility for oxometallacycle formation between the EG molecule and the metal nanoparticles in the catalyst when EG is directly used results in a strongly bonded intermediate which is responsible for carbon deposition, whereas the hydrolysis of MEX into EG+MET over the catalyst results in more reactive intermediates towards SR. 
Table 5: Molar ratio of inlet hydrogen (by water+fuel) to inlet carbon (by fuel) for SR experiments

\begin{tabular}{ccccc}
\hline SR experiment & MEX & EG+MET & EG & MET \\
\hline $\mathrm{H}_{2}^{\text {in }} / \mathrm{C}^{\text {in }}$ & 4.3 & 4.7 & 4.5 & 5 \\
\hline
\end{tabular}

\section{Conclusion}

2-Methoxyethanol, ethylene glycol, and methanol steam reforming experiments were performed in a catalytic membrane reactor containing $\mathrm{RhPd} / \mathrm{CeO}_{2}$ catalyst pellets and $\mathrm{Pd}$ Ag dense metallic membranes at $923 \mathrm{~K}$ and 1-10 bar aiming to produce pure hydrogen. 2Methoxyethanol steam reforming showed promising results in terms of pure hydrogen production. The effect of the hydrogen permeation through the membrane on the performance of the CMR was studied by running the experiments both with open and closed membrane. Hydrogen yield and recovery of 0.6 and $86 \%$ were reached at 10 bar. In the case of the steam reforming (SR) of a mixture of ethylene glycol and methanol (EG+MET), hydrogen yield increased up to 0.63 because the first step of the 2Methoxyethanol SR process, which is the hydrolysis into EG+MET, was not necessary. The production rates of SR products $\left(\mathrm{CH}_{4}, \mathrm{CO}, \mathrm{CO}_{2}\right.$, and $\left.\mathrm{H}_{2}\right)$ and carbon recovery showed that the SR of EG was strongly promoted by methanol.

\section{Acknowledgements}

Funding from MINECO project ENE2015-63969-R is acknowledged. J.L. is Serra Húnter Fellow and is grateful to ICREA Academia program. 
References

[1] Simpson AP, Lutz A. Exergy analysis of hydrogen production via steam methane reforming. Int J Hydrogen Energy 2007;32:4811-20.

doi:10.1016/j.jjhydene.2007.08.025.

[2] Llorca J, Cortés Corberán V., Divins J.N., Fraile R.O., Elena Taboada E. Hydrogen from bio-ethanol. In: Gandía LM, Arzamendi G D, PM E, editors. Renew. Hydrog. Technol., Amsterdam: Elsevier; 2013. doi:10.1016/B978-0-444-56352-1.00007-6.

[3] Llorca J, Hedayati A. Alcohols and Bio-alcohols Steam and Autothermal Reforming in a Membrane Reactor. In: Angelo Basile, Dalena F, editors. Alcohols Bioalcohols Charact. Prod. Uses, New York, USA: NOVA Publication; 2014, p. 181-204.

[4] Resende KA, Ávila-Neto CN, Rabelo-Neto RC, Noronha FB, Hori CE. Hydrogen production by reforming of acetic acid using La-Ni type perovskites partially substituted with Sm and Pr. Catal Today 2015;242:71-9. doi:10.1016/j.cattod.2014.07.013.

[5] Gil M V., Fermoso J, Pevida C, Chen D, Rubiera F. Production of fuel-cell grade H2 by sorption enhanced steam reforming of acetic acid as a model compound of biomass-derived bio-oil. Appl Catal B Environ 2015;184:64-76.

doi:10.1016/j.apcatb.2015.11.028.

[6] Zhao X, LÜ Y, Liao W, Jin M, Suo Z. Hydrogen production from steam reforming of ethylene glycol over supported nickel catalysts. J Fuel Chem Technol 2015;43:5818. doi:10.1016/S1872-5813(15)30017-7.

[7] Izquierdo U, Wichert M, Kolb G, Barrio VL, Zapf R, Ziogas A, et al. Micro reactor hydrogen production from ethylene glycol reforming using Rh catalysts supported 
on CeO2 and La2O3 promoted $\alpha-A l 2 O 3$. Int J Hydrogen Energy 2014;39:5248-56. doi:10.1016/j.jjhydene.2013.12.170.

[8] Wang N, Perret N, Foster A. Sustainable hydrogen production for fuel cells by steam reforming of ethylene glycol: A consideration of reaction thermodynamics. Int J Hydrogen Energy 2011;36:5932-40. doi:10.1016/j.ijhydene.2011.01.140.

[9] Roses L, Gallucci F, Manzolini G, van Sint Annaland M. Experimental study of steam methane reforming in a Pd-based fluidized bed membrane reactor. Chem Eng J 2013;222:307-20. doi:10.1016/j.cej.2013.02.069.

[10] Sheintuch M. Pure hydrogen production in a membrane reformer: Demonstration, macro-scale and atomic scale modeling. Chem Eng J 2015;278:363-73. doi:10.1016/j.cej.2014.11.100.

[11] Badmaev SD, Pechenkin AA, Belyaev VD, Ven'yaminov SA, Snytnikov P V., Sobyanin VA, et al. Steam reforming of dimethoxymethane to hydrogen-rich gas for fuel cell feeding application. Dokl Phys Chem 2013;452:251-3. doi:10.1134/S0012501613100060.

[12] Badmaev SD, Pechenkin AA, Belyaev VD, Sobyanin VA. Hydrogen production by steam reforming of dimethoxymethane over bifunctional $\mathrm{CuO}-\mathrm{ZnO} / \mathrm{v}-\mathrm{Al} 2 \mathrm{O} 3$ catalyst. Int J Hydrogen Energy 2015;40:14052-7. doi:10.1016/j.ijhydene.2015.05.188.

[13] Preece JC. Oxynated hydrocarbon fuels for solid oxide fuel cells. The University of Birmingham, 2005.

[14] Wakabayashi N, Takeuchi K, Uchida H, Watanabe M. Characterization of Methoxy Fuels for Direct Oxidation-Type Fuel Cell. J Electrochem Soc 2004;151:A1636. doi:10.1149/1.1793191. 
[15] Chetty R, Scott K. Dimethoxymethane and trimethoxymethane as alternative fuels for fuel cells. J Power Sources 2007;173:166-71.

doi:10.1016/j.jpowsour.2007.07.068.

[16] Jiménez Divins N. Catalytic hydrogen production over RhPd / CeO 2 catalysts and $\mathrm{CO}$ purification over $\mathrm{Au} / \mathrm{TiO}_{2}$ catalysts. Universitat Politècnica de Catalunya, 2015.

[17] O'Neil MJ, editor. The Merck Index: An Encyclopedia of Chemicals, Drugs, and Biologicals. 13th ed. Cabbridge, UK: Royal Society of Chemistry; 2013.

[18] Marton S. Renewable Ethylene. CHALMERS UNIVERSITY OF TECHNOLOGY, 2013.

[19] Martijn Broeren; Ruud Kempener; Giorgio Simbolotti ; Giancarlo Tosato. Production of Bio-ethylene: Technology Brief. 2013. doi:10.1111/j.1745-4514.2010.00447.x.

[20] Lynch S, Eckert C, Yu J, Gill R, Maness P-C. Overcoming substrate limitations for improved production of ethylene in E. coli. Biotechnol Biofuels 2016;9. doi:10.1186/s13068-015-0413-x.

[21] Eckert C, Xu W, Xiong W, Lynch S, Ungerer J, Tao L, et al. Ethylene-forming enzyme and bioethylene production. Biotechnol Biofuels 2014;7. doi:10.1186/17546834-7-33.

[22] Lukyanov BN, Andreev DV, Parmon VN. Catalytic reactors with hydrogen membrane separation. Chem Eng J 2009;154:258-66. doi:10.1016/j.cej.2009.04.023.

[23] Sánchez JM, Barreiro MM, Maroño M. Bench-scale study of separation of hydrogen from gasification gases using a palladium-based membrane reactor. Fuel 2014;116:894-903. doi:10.1016/j.fuel.2013.02.051. 
[24] Gallucci F, Basile A. Pd-Ag membrane reactor for steam reforming reactions: A comparison between different fuels. Int J Hydrogen Energy 2008;33:1671-87. doi:10.1016/j.jjhydene.2008.01.010.

[25] Basile A. Hydrogen Production Using Pd-based Membrane Reactors for Fuel Cells. Top Catal 2008;51:107-22. doi:10.1007/s11244-008-9128-6.

[26] Mendes D, Tosti S, Borgognoni F, Mendes A, Madeira LM. Integrated analysis of a membrane-based process for hydrogen production from ethanol steam reforming. Catal Today 2010;156:107-17. doi:10.1016/j.cattod.2010.02.029.

[27] Jiwanuruk T, Putivisutisak S, Ponpesh P, Bumroongsakulsawat P, Tagawa T, Yamada $\mathrm{H}$, et al. Effect of flow arrangement on micro membrane reforming for $\mathrm{H} 2$ production from methane. Chem Eng J 2016;293:319-26. doi:10.1016/j.cej.2016.02.075.

[28] Gao H, Lin YS, Li Y, Zhang B. Chemical Stability and Its Improvement of PalladiumBased Metallic Membranes. Ind Eng Chem Res 2004;43:6920-30. doi:10.1021/ie049722f.

[29] Idriss H, Scott M, Llorca J, Chan SC, Chiu W, Sheng P-Y, et al. A phenomenological study of the metal-oxide interface: the role of catalysis in hydrogen production from renewable resources. ChemSusChem 2008;1:905-10. doi:10.1002/cssc.200800196.

[30] López E, Divins NJ, Llorca J. Hydrogen production from ethanol over $\mathrm{Pd}-\mathrm{Rh} / \mathrm{CeO} 2$ with a metallic membrane reactor. Catal Today 2012;193:145-50. doi:10.1016/j.cattod.2012.06.030.

[31] Domínguez M, Taboada E, Molins E, Llorca J. Ethanol steam reforming at very low 
temperature over cobalt talc in a membrane reactor. Catal Today 2012;193:101-6. doi:10.1016/j.cattod.2012.02.004.

[32] Hedayati A, Le Corre O, Lacarrière B, Llorca J. Experimental and exergy evaluation of ethanol catalytic steam reforming in a membrane reactor. Catal Today 2016;268:68-78. doi:10.1016/j.cattod.2016.01.058.

[33] Kechagiopoulos PN, Voutetakis SS, Lemonidou AA, Vasalos IA. Sustainable hydrogen production via reforming of ethylene glycol using a novel spouted bed reactor. Catal Today 2007;127:246-55. doi:10.1016/j.cattod.2007.05.018.

[34] Vagia EC, Lemonidou AA. Thermodynamic analysis of hydrogen production via autothermal steam reforming of selected components of aqueous bio-oil fraction. Int J Hydrogen Energy 2008;33:2489-500. doi:10.1016/j.ijhydene.2008.02.057. 